\title{
Stabilization of hydraulic characteristics for non-pressure pipelines
}

\author{
Vladimir Orlov* and Sergey Zotkin \\ Moscow State University of Civil Engineering, Yaroslavskoe shosse, 26, Moscow, 129337, Russia
}

\begin{abstract}
The article presents the aspects concerning the preservation of the transporting capacity of the waste water flow in the gravity pipeline during its trenchless renovation by polymer pipes. It is shown that the priority measure to preserve the required degree of self-cleaning of the restored pipeline section, as well as these ones adjacent to it, are the values of the water flow rate and filling in the pipe, which allows to provide the necessary transportation capacity of the entire pipeline system. A formula for determining the length of the rate destabilization zone is proposed and the calculation results using an automated program are given. The program algorithm includes the functions to determine the hydraulic friction coefficients of the pipeline material depending on various parameters, as well as the diameters and lengths of all sections. The essence of the calculations using an automated complex is described and the comparison of the calculation results under different conditions is made. There are given practical recommendations for the potential achievement of the hydraulic balance in the pipeline system and the creation of conditions under which the destabilization zone on the site after the repair becomes minimal.
\end{abstract}

\section{Introduction}

The wide use of trenchless technologies for the restoration and construction of pipeline communications has many positive aspects, which are based primarily on the achievement of economic and environmental effects, as well as the efficiency of construction and installation works $[1,2]$. Trenchless repair works at the pipelines is often cheaper than their replacement by digging the earth and construction of trenches and pits $[3,4]$.

At the moment, the methods of dragging new pipes or sleeves (stockings) mainly from polymeric materials [5] are the most widely used in the practice of reconstruction and modernization of gravity and pressure pipeline networks. Every year, the construction markets offer new composite materials that can meet the stringent requirements for the strength and hydraulic characteristics of engineering networks under restoration [6].

When designing repair and restoration works by trenchless methods of stretching new pipes into the old pipeline, it is necessary to goal the conditions of hydraulic compatibility of the network sections [7]. For gravity pipelines this problem is directly related to the

\footnotetext{
* Corresponding author: zotkinsp@mgsu.ru
} 
transporting capacity of the waste liquid flow in the drainage pipes, which is primarily determined by the calculated water flow rate, which provides self-cleaning of pipes and collectors, as well as their filling. Before making a final decision on the method of reconstruction of an object, it is necessary to conduct a qualitative diagnosis of its state [8, 9].

Considering in detail the aspects of the waste liquid flow transporting capacity, the researchers are interested in identifying both the absolute rate values and the analysis of the non-equivalence of the impurity transportation rates on the surface, in the flow depth and in the tray part of the pipe when moving sediments. The research results show that the more undissolved impurities in water and the larger they are, the greater the flow resistance is [10]. As a result of the resistances encountered by the flow, the solid particles move from layer to layer towards the tray. In trays an insufficient rate caused by the increasing mass of suspended particles may lead to formation of bottom sediments, which will be compacted with the time [11]. It should be noted that the empirical formulas for determining the nonsilting rate, which have been got by the researchers in different years, are mainly characteristic of the sand transportation conditions [12].

\section{Methods. The theoretical justification of the hydraulic imbalance occurrence after carrying out repair works on pipelines}

The experts noted that during the repair works on any part of the pipeline by applying internal protective coatings having a smooth surface, the phenomenon of the rate imbalance at the subsequent sections is not excluded [13]. Flowing from the repaired (new) site, which is, as a rule, of smaller roughness, to the old (not restored) one with bigger roughness the water begins to lose rate due to differing roughness and diameter, i.e. the movement of the liquid becomes equidistant in a certain part along the length of the site, which can be called as the rate destabilization zone.

Along this distance, as a result of a kind of braking, some backwater can be observed and a suspension can be deposited with the formation of sediment ridges. Over time the sediments can pass to the stage of permanent indelible dense deposits. This is the imbalance of the pipeline operation [14]. If the designers do not provide appropriate countermeasures against the potential hydraulic imbalance, the responsibility of the service bodies, which bear responsibility of the drainage pipeline operation, increases dramatically. In this case, the tasks of the operation services will include the elimination of possible consequences resulting in an additional (preventive) cleaning of the pipeline network sections. First of all, it will affect the sections, which lay after the restored area, i.e. the need of timely removal of dense indelible sediments accumulated on the bottom part of these sections.

On the basis of the practical experience and theoretical developments aimed at creating a hydraulic model of the pipeline operation and getting a formula for determining the length of the rate destabilization zone $S, \mathrm{~m}(1)$ :

$$
S=\left(V_{0}^{2}-V_{\mathrm{K}}^{2}\right) /\left[\left(\lambda \cdot V_{0}^{2} / 4 R\right)-2 g \cdot i\right],
$$

where $V_{0}, V_{\mathrm{K}}$ are the rates in the restored area in the next (unrepaired) one along the current of the liquid flow; $\mathrm{m} / \mathrm{s}$;

$\lambda$ - coefficient of hydraulic friction of the material of the restored section; $R$-hydraulic radius, $\mathrm{m} ; i$ - the pipeline slope; $\mathrm{g}$ - acceleration of gravity, $\mathrm{m} / \mathrm{s}^{2}$.

The use of the formula (1), describing the dependence of the destabilization zone on the pipeline hydraulic friction coefficients, their slopes, the hydraulic radius and the flow rates, allowed to develop an algorithm and an automated program [15]. 
The whole complex of the Chézy's $C$ coefficient hydraulic calculations has been made by the automated program with the use of three alternative formulas describing the gravity flow modes in drainage pipes made of various materials:

- by Pavlovskiy: $C=(1 / n) \cdot R^{y}$

where $y=2,5 \cdot n^{0,5}-0,13-0,75 \cdot R^{0,5} \cdot\left(n^{0,5}-0,1\right)$

- by Altshul: $C=20 \cdot \lg \left[R /\left(\varepsilon+0,004 /(R \cdot i)^{0,5}\right)\right]$,

- by Manning: $C=(1 / n) \cdot R^{1 / 6}$

where $\varepsilon$ is the reduced linear roughness, $\mathrm{mm}, n$ - the roughness coefficient.

The indicators (factors, criteria) that are used in the formulas are adapted to the actual materials of pipelines and comply with the recommendations of A.I. Dobromyslov on the hydraulic calculation of the plastic pipes, as well as the reference data on the surface roughness of the pipes made of different materials [16].

The program offers the researcher a wide range of opportunities, in particular, for the designer. It can analyze the situation in the pipeline through consideration of alternative solutions for the replacement (renovation) of one of the pipeline section and tracking changes in hydraulic characteristics when modifying diameters, costs, slopes, etc. The ultimate goal of this study is to find the optimal design option, i.e. to determine the conditions when the rate destabilization zone $S$ becomes the smallest or absent completely. This will allow in the long term to reduce the number of cases of possible flooding in certain sections of the pipeline, eliminating the backwater due to the formation of compacted sediments on the tray part of the pipes.

The positive side of the modeling of the occurring phenomena, fixing the dynamics of changes in hydraulic indicators, is that the automated program allows a specialist to make a comprehensive assessment of the situation and choose the most suitable design option of repair, restoration and other works in the area under investigation $[17,18]$.

A fragment of the pipeline system, including three sections, the middle of which was subjected to a trenchless renovation by dragging into it and fixing a thin-walled polymer pipe narrowing the inner diameter, was considered as the object of the investigation. The process of modeling the situation with finding an acceptable option (minimum rate imbalance zone) was aimed at obtaining the design information on the whole complex of hydraulic and geometric characteristics of the flow due to the surplus within a certain range of the water consumption and possible changes in other parameters.

Thus, as a result of the automated complex operation, the management tasks to optimize the repair and restoration work in terms of compliance with the hydraulic characteristics of the fragment of the pipeline system consisting of three sections were fully manifested.

The Figure 1 shows, as an example, the automated program interface with a stylized image of the pipeline sections. 


Eithdraulic compatibility
\begin{tabular}{|c|c|c|c|}
\hline Calculate & Output & Destabilization zone \\
\hline
\end{tabular}
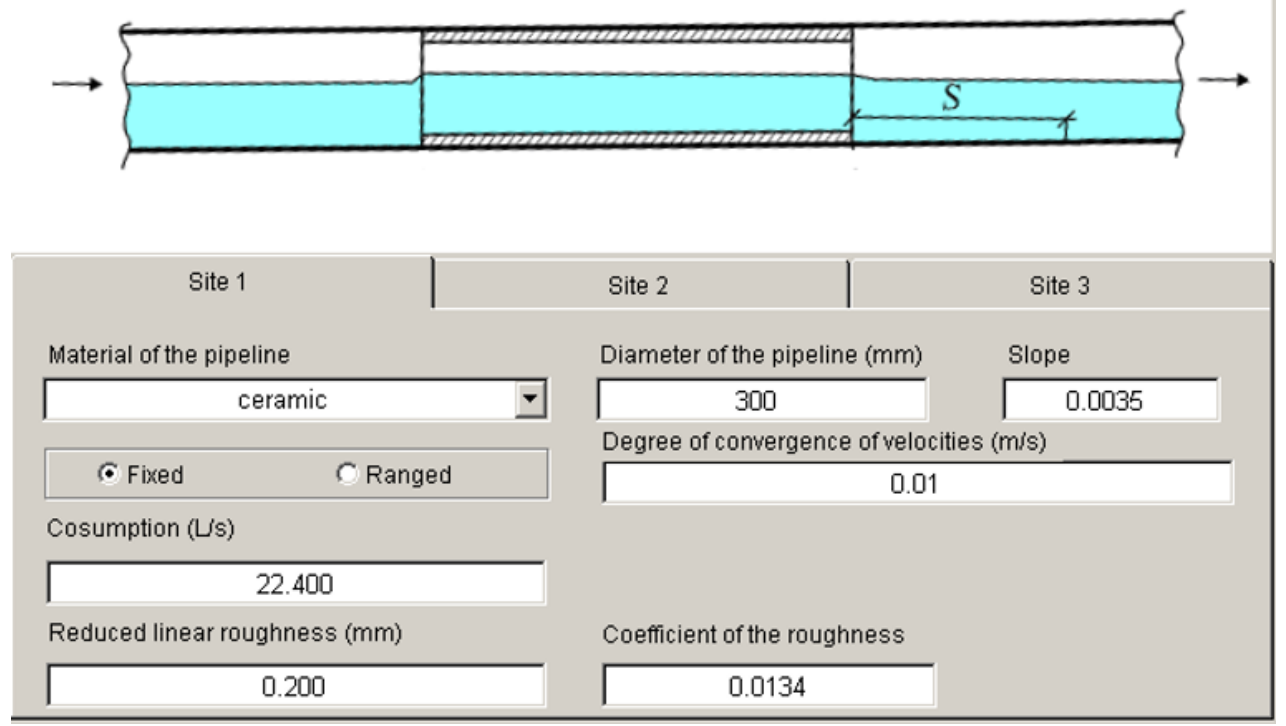

Fig. 1. General view of the automated program dialog box with information on sections in any form.

Work of the program user consists in consecutive performance of the following operations:

-data entry and determination of the length of the rate destabilization zone in the last (third) section;

-analysis of the calculated data by options with the adjustment of the initial parameters to ensure the hydraulic compatibility of old and new pipeline sections and the description of alternative measures for elimination of the hydraulic imbalance phenomena (if any);

-justification of the most preferred option of repair and restoration works from among the proposed ones for consideration.

The program enables printing out both intermediate and final tables with information on hydraulic calculations of the drainage pipeline and identification of the presence (absence) of hydraulic compatibility in adjacent areas of the drainage pipeline (under repair and the next one).

\section{Results and discussions (interpretation of the results)}

The simulation results with numerical values of hydraulic and geometrical parameters and their analysis for two cases are presented below.

\subsection{The first case}

The object of the investigation (design) is a pipeline system, which includes a sequence of sections: ceramic pipe (diameter $150 \mathrm{~mm}$ ), polyethylene pipe (diameter $125 \mathrm{~mm}$ ) and ceramic pipe (diameter $150 \mathrm{~mm}$ ). The slope of the pipeline at the sites varied in the range of $0.0066-0.017$, and the water consumption remained constantly $81 / \mathrm{s}$. 
The ultimate objective of the simulation was to calculate the length of the rate destabilization zone under a new construction to formulate recommendations for the trenchless restoration of one of the pipeline system sections.

The printout of the output data for the second and the third sections is shown in the Table 1.

Table 1. Hydraulic and geometrical parameters of the first simulation case

\begin{tabular}{|l|c|c|c|c|c|c|c|}
\hline \multirow{2}{*}{$\begin{array}{c}\text { The formula } \\
\text { to determine } \\
\text { the Chézy's } C \\
\text { coefficient }\end{array}$} & \multicolumn{5}{|c|}{$\begin{array}{c}\text { Site 2 } \\
\text { (polyethylene pipe) }\end{array}$} & \multicolumn{5}{|c|}{$\begin{array}{c}\text { Site } 3 \\
\text { (ceramic pipe) }\end{array}$} \\
\cline { 2 - 9 } & Slope & $\begin{array}{c}\text { Consum } \\
\text { ption, } \\
1 / \mathrm{s}\end{array}$ & $\begin{array}{c}\text { Rate, } \\
\mathrm{m} / \mathrm{s}\end{array}$ & Slope & $\begin{array}{c}\text { Consum } \\
\text { ption, } \\
1 / \mathrm{s}\end{array}$ & $\begin{array}{c}\text { Rate, } \\
\text { m/s }\end{array}$ & $\begin{array}{c}\text { Destabilizati } \\
\text { on zone } \\
\text { length } S, \mathrm{~m}\end{array}$ \\
\hline by Pavlovskiy & 0.0066 & 8.0 & 1.058 & 0.0066 & 8.0 & 0.767 & 4.58 \\
\hline by Altshul & 0.0066 & 8.0 & 1.074 & 0.0066 & 8.0 & 0.753 & 4.53 \\
\hline by Manning & 0.0066 & 8.0 & 1.062 & 0.0066 & 8.0 & 0.761 & 4.56 \\
\hline by Pavlovskiy & 0.0066 & 8.0 & 1.058 & 0.008 & 8.0 & 0.826 & 4.29 \\
\hline by Altshul & 0.0066 & 8.0 & 1.074 & 0.008 & 8.0 & 0.811 & 4.27 \\
\hline by Manning & 0.0066 & 8.0 & 1.062 & 0.008 & 8.0 & 0.815 & 4.27 \\
\hline by Pavlovskiy & 0.0066 & 8.0 & 1.058 & 0.009 & 8.0 & 0.863 & 4.23 \\
\hline by Altshul & 0.0066 & 8.0 & 1.074 & 0.009 & 8.0 & 0.848 & 4.16 \\
\hline by Manning & 0.0066 & 8.0 & 1.062 & 0.009 & 8.0 & 0.897 & 4.18 \\
\hline by Pavlovskiy & 0.0066 & 8.0 & 1.058 & 0.01 & 8.0 & 0.898 & 4.10 \\
\hline by Altshul & 0.0066 & 8.0 & 1.074 & 0.01 & 8.0 & 0.883 & 4.06 \\
\hline by Manning & 0.0066 & 8.0 & 1.062 & 0.01 & 8.0 & 0.899 & 4.09 \\
\hline by Pavlovskiy & 0.0066 & 8.0 & 1.058 & 0.011 & 8.0 & 0.931 & 3.95 \\
\hline by Altshul & 0.0066 & 8.0 & 1.074 & 0.011 & 8.0 & 0.915 & 3.59 \\
\hline by Manning & 0.0066 & 8.0 & 1.062 & 0.011 & 8.0 & 0.922 & 3.69 \\
\hline by Pavlovskiy & 0.0066 & 8.0 & 1.058 & 0.0154 & 8.0 & 1.058 & 0 \\
\hline by Altshul & 0.0066 & 8.0 & 1.074 & 0.017 & 8.0 & 1.074 & 0 \\
\hline by Manning & 0.0066 & 8.0 & 1.062 & 0.0163 & 8.0 & 1.062 & 0 \\
\hline
\end{tabular}

The analysis of the design data in Table 1 shows the following:

- there is a fairly stable tendency of reduction of the difference in flow rates between the site 2 and the site 3 within the entire range of the studied slope values; and the results of the calculation using the formulas of Pavlovsky and Altshul (as having the greatest discrepancies in the calculated range of values), however, are comparable, which indicates their possible interchange;

-the length of the rate destabilization zone has a weak tendency to decrease to $3.59 \mathrm{~m}$ due to the increase in slope on the site 3 from 0.008 to 0.011 ;

-with a significant change in the slope, for example, from 0.0154 to 0.017 , the destabilization zone disappears (both in the calculation according to the formulas by N. N. 
Pavlovskiy and A.D.Altshul); this fact can be used by designers when making a decision on the choice of parameters of the pipeline system under restoration);

- disappearance (absence) of the rate destabilization zone occurs at equal rate values on the third and the second sites (respectively 1.058 and $1.074 \mathrm{~m} / \mathrm{s}$ );

- the critical slope at which the destabilization disappears makes 0.0154 when calculating according to the formula of N.N. Pavlovskiy and 0.0169 according to the formula of A. D. Altshul. It shows, in general, a high convergence of the results by both formulas (the difference is $8.88 \%$ ) and indicates the possibility of their mutual interchange as well.

The simulation showed, that when the water consumption in the pipeline system changes to $10 \mathrm{l} / \mathrm{s}$, the length of the destabilization zone increases to $5.08 \mathrm{~m}$ and at $12 \mathrm{l} / \mathrm{s}-$ to $5.33 \mathrm{~m}$ (if calculated according to the formula of N.N. Pavlovskiy ). The similar trends are observed in the calculations according to the formula of A. D. Altshul (4.97 and $5.14 \mathrm{~m}$, respectively).

Thus, the obtained results show their usefulness when being applied in the design practice at the moment of making a decision on the choice of parameters of the pipeline system to be restored. If we transfer the got results to the trenchless renovation facilities, where the site 2 will have a deliberately smaller diameter than the neighboring ones, the destabilization zone will be really inevitable. The practice of the pipeline operation servicing works and their modeling show that the reduction of waste water consumption leads to a decrease in the destabilization zone length. However, it is difficult to foresee a theoretically unambiguous result in terms of the size of the destabilization zone without the use of a software package (with a wide range of changes in all hydraulic parameters).

\subsection{The second case}

In this case the alternative option of carrying out repair and restoration works has been considered, when the site 2 under repair has to be renovated by trenchless method without destruction of the old area and pulling a new polyethylene pipe of a smaller diameter. The task imposed the original diameter of $150 \mathrm{~mm}$ of the pipes in the three sections. The Section 2 (to be restored) after the reconstruction works had the following characteristics: the outer diameter of $0.125 \mathrm{~m}$, the inner diameter of $0.115 \mathrm{~m}$ and the wall thickness of $0.0049 \mathrm{~m}$ ). Thus, the internal diameters of the pipelines in the sections were, respectively, $150-115-150 \mathrm{~mm}$, the minimum permissible slope of the pipes in all three sections was 0.0066 , the consumption of the transported wastewater was $81 / \mathrm{s}$. The Table 2 presents the printout of the design values of the hydraulic parameters for the second and the third sites. 
Table 2. Hydraulic and geometrical parameters of the second simulation case

\begin{tabular}{|c|c|c|c|c|c|c|c|}
\hline \multirow{2}{*}{$\begin{array}{l}\text { The formula } \\
\text { to determine } \\
\text { the Chézy's } C \\
\text { coefficient }\end{array}$} & \multicolumn{3}{|c|}{$\begin{array}{c}\text { Site } 2 \\
\text { (restored, of polyethylene pipe) }\end{array}$} & \multicolumn{4}{|c|}{$\begin{array}{c}\text { Site } 3 \\
\text { (non-restored, of ceramic pipe) }\end{array}$} \\
\hline & Slope & $\begin{array}{c}\text { Consum } \\
\text { ption, } \\
1 / \mathrm{s}\end{array}$ & $\begin{array}{c}\text { Rate, } \\
\mathrm{m} / \mathrm{s}\end{array}$ & Slope & $\begin{array}{c}\text { Consum } \\
\text { ption, } \\
1 / s\end{array}$ & $\begin{array}{c}\text { Rate, } \\
\mathrm{m} / \mathrm{s}\end{array}$ & $\begin{array}{c}\text { Destabiliz } \\
\text { ation zone } \\
\text { length } S, \\
\text { m }\end{array}$ \\
\hline by Pavlovskiy & 0.0066 & 8.0 & 1.044 & $\begin{array}{c}0.006 \\
6\end{array}$ & 8.0 & 0.767 & 4.57 \\
\hline by Altshul & 0.0066 & 8.0 & 1.06 & $\begin{array}{c}0.006 \\
6\end{array}$ & 8.0 & 0.753 & 4.49 \\
\hline by Manning & 0.0066 & 8.0 & 1.052 & $\begin{array}{c}0.006 \\
6\end{array}$ & 8.0 & 0.762 & 4.51 \\
\hline by Pavlovskiy & 0.0066 & 8.0 & 1.044 & 0.008 & 8.0 & 0.826 & 4.31 \\
\hline by Altshul & 0.0066 & 8.0 & 1.06 & 0.008 & 8.0 & 0.811 & 4.24 \\
\hline by Manning & 0.0066 & 8.0 & 1.052 & 0.008 & 8.0 & 0.817 & 4.28 \\
\hline by Pavlovskiy & 0.0066 & 8.0 & 1.044 & 0.009 & 8.0 & 0.863 & 4.23 \\
\hline by Altshul & 0.0066 & 8.0 & 1.06 & 0.009 & 8.0 & 0.848 & 4.17 \\
\hline by Manning & 0.0066 & 8.0 & 1.052 & 0.009 & 8.0 & 0.852 & 4.21 \\
\hline by Pavlovskiy & 0.0066 & 8.0 & 1.044 & 0.01 & 8.0 & 0.898 & 4.10 \\
\hline by Altshul & 0.0066 & 8.0 & 1.06 & 0.01 & 8.0 & 0.883 & 4.06 \\
\hline by Manning & 0.0066 & 8.0 & 1.052 & 0.01 & 8.0 & 0.890 & 4.08 \\
\hline by Pavlovskiy & 0.0066 & 8.0 & 1.044 & 0.011 & 8.0 & 0.931 & 3.94 \\
\hline by Altshul & 0.0066 & 8.0 & 1.06 & 0.011 & 8.0 & 0.915 & 3.57 \\
\hline by Manning & 0.0066 & 8.0 & 1.052 & 0.011 & 8.0 & 0.928 & 3.81 \\
\hline by Pavlovskiy & 0.0066 & 8.0 & 1.044 & $\begin{array}{c}0.015 \\
4\end{array}$ & 8.0 & 1.044 & 0 \\
\hline by Altshul & 0.0066 & 8.0 & 1.06 & 0.017 & 8.0 & 1.06 & 0 \\
\hline by Manning & 0.0066 & 8.0 & 1.052 & $\begin{array}{c}0.016 \\
3\end{array}$ & 8.0 & 1.052 & 0 \\
\hline
\end{tabular}

The analysis of the calculated data of Tables 1 and 2 shows the following: the established regularities in the first case are almost identical to the second case. The explanation for this can be the study of the nature of the change in the ratio "filling - rate», where a constant water consumption and narrowing of the pipeline at the site under repair, when there is an obvious increase in filling, a slight decrease in the flow rate may be stated: 1.321 and $1.303 \%$ in the calculations, respectively, according to the formulas of N.N. Pavlovskiy and A.D. Altshul. The data obtained indicate that when replacing an old section of the pipeline with a new one made of a polymer material, regardless of its diameter, there will be present a rate destabilization zone. 
If the length of the destabilization zones is insignificant, for example, about 1-1.5 m, i.e. they are comparable to the length of the open tray of the observation well or if they are quite large, i.e. exceed the length of the subsequent part of the pipeline, then, obviously, no measures are required to correct the negative situation with the presence of the rate destabilization zone.

In case when a destabilization zone does not exceed the length of the subsequent part of the pipeline, i.e. is comparable to it, the phenomena of flooding in places where the flow rate are equidistant, will not be excluded. One way out of this situation can be provision of restoration works at a longer pipeline site (several sites) to the nearest difference well or even to the point of coupling with the pipeline, which has such a diameter and a slope that ensure hydraulic compatibility in the passage of the design flow consumption.

\section{Conclusions}

1. The practical results on the detection of the violation of the drainage pipeline transporting capacity are analyzed, as well as the theoretical dispositions aimed at determination of the rate destabilization zone in the adjacent areas of the drainage pipeline under trenchless method renovation by pulling new polymer pipes into the old pipeline are presented.

2. The principle of operation of the hydraulic value calculation automated program of the adjacent pipeline sites under renovation is described.

3. The calculation results, which have been got by the automated complex, and their subsequent analysis enabled setting of the intervals of possible hydraulic parameter destabilization zones using alternative mathematical dependences to determine the Chézy's $\mathrm{C}$ coefficient, as well as the options that exclude hydraulic imbalance have been proposed.

\section{References}

1. Kuliczkowski A., Kuliczkowska E., Zwierzchowska A. Technologie beswykopowe w inzeynierii srodowiska. Wydawnictwo Seidel-Przywecki Sp. (2010). 735 p.

2. Khramenkov S.V., Primin O.G., Orlov V.A. Reconstruction of pipeline systems. ASV. (2008) 215 p. (rus)

3. Bremond B., Konig A., Le Gat Y., Saegrov S., Torterotot J.-Ph., Werey C. Vers une maintenance et une rehabilitation preventives des reseaux d'assainissement. Techn., sci., meth. 9 (2004), p. 71-75.

4. Zakharov Yu.S. Experience Of Germany. Trenchless repair of water disposal systems. Journal of technology of the World. 1(39) (2012) p. 31-38 (rus)

5. Zwierzchowska A. Technologie bezwykopowej budowy sieci gazowych, wodociagowych i kanalizacyjnych. Politechnika swietokrzyska. (2006) p. 180

6. Bergue J.-M., Joussin J.-M., Orditz D., Thépot O. New design of liners in gravity flow pipes French recommendations 3R-(2014) 32 International NO-DIG Conference, Madrid, 13-15 October 2014. Ref. 6A-4, p. 1-10

7. Altschul A.D., Calitzyn V.I., Mayranovsky F.G., P.P. Palgunov Examples of calculations for hydraulics. -M.: Alliance (2013). 255 p. (rus)

8. Iyer S. Sinha K. /Automated condition assessment of buried sewer pipes based on digital imaging techniques./ J. Indian Inst. Sci. 85(5) (2005) p. 235-252

9. Rameil M. Handbook of pipe bursting practice. Vulkan verlag.(2007)

10. Arolla S.K. Desjardins O. Transport modeling of sedimenting particles in a turbulent pipe flow using Euler-Lagrange large eddy simulation. International Journal of Multiphase Flow . (2015). p. 734-750 
11. Church M. Bed material transport and the morphology of alluvial river channels Annual Review of Earth and Planetary Sciences. 34 (1) (2006) p. 325-354.

12. Khrenov K. E., Pakhomov A. N., Bogomolov, M. V., Dudchenko T. O., Pronin A. A. Modern technologies and equipment to upgrade networks and Sewerage Journal Water supply and sanitary technique. 10 (2008). p. 15-24 (rus)

13. Otstavnov A. A., Khar'kin V. A. On the kinetic possibilities of the reconstructed sections of the old sewer pipelines. Plumbing. 6 (2004) p. $42-46$ (rus)

14. Khrenov K. E., Romashkin O. V. improving the reliability of the sewer system in Moscow in emergency situations Journal of water Supply and sanitary engineering. 1 (2006) p. 22-24 (rus)

15. Khramenkov S. V., Primin O. G., Zotkin S. P., Harkin V. A. Device for the analysis of reliability of pipelines of the city drainage network. Russian patent for utility model No. 31137, Published: 20.03.2013

16. Dobromyslov A. J. Hydraulic calculation of non-pressure pipelines.Journal of Pipelines and the environment. 2 (2000) p. 21-24 (rus)

17. Ignatova E. Solution of problems on the base of building information models. Vestnik MGSU Proceedings of Moscow State University of Civil Engineering. 9 (2012) - p. 241-246

18. Gamayunova O. Vatin N. BIM-technology in architectural design. Advanced Materials Research. 1065-1069 (2015) p. 2611-2614 